Supplementary material

Creating drug solubilisation compartments via phase separation in multicomponent buccal patches prepared by direct hot melt extrusion-injection moulding

Muqdad Alhijjaj ${ }^{1,2}$, Jacob Bouman ${ }^{3,4}$, Nikolaus Wellner ${ }^{5}$, Peter Belton ${ }^{6}$, Sheng ${ }^{1{ }^{*}}$

1. School of Pharmacy, University of East Anglia, Norwich, Norfolk, UK, NR4 $7 T J$

2. College of Pharmacy, University of Basrah, Basrah, Iraq

3. Laboratory of Physical Chemistry and Colloid Science, Wageningen

University, Wageningen, The Netherlands

4. Physics and Physical Chemistry of Foods, Wageningen University,

Wageningen, The Netherlands

5. Institute of Food Research, Norwich Research Park, Colney Lane, Norwich, Norfolk, NR4 7UA

6. School of Chemistry, University of East Anglia, Norwich, Norfolk, UK, NR4

$7 T J$

Correspondence: Sheng Qi, sheng.qi@uea.ac.uk 


\section{List of content:}

1. Figure 1. Images of the felodipine extrudates and patches prepared at $65{ }^{\circ} \mathrm{C} ; \mathrm{A}$ ) Placebo extrudate, B) Placebo buccal patch, C) 10\% w/w felodipine extrudate, D) $10 \%$ felodipine buccal patch, E) $20 \%$ w/w felodipine extrudate, F) $20 \%$ felodipine buccal patch, G) 30\% w/w felodipine extrudate, H) 30\% felodipine buccal patch.

2. Estimation of miscibility of PEG/PEO and felodpine using group contribution method. (Table 1-4, Figure 2)

3. Table 5. Melting point (M.P) depression of PEG/PEO blend caused by drug loading in different patches (3 replicates for each sample) $\mathrm{DSC} 10^{\circ} \mathrm{C} / \mathrm{min}$.

4. Analysis of the $T_{\mathrm{g}}$ regions of the systems (Table 6)

5. Figure 3. (a) IR reflectance spectra coding for the composition of different colors in the IR images. Red spectrum indicates areas containing drug as molecularly dispersed or amorphous form; green spectrum indicating areas indicating areas rich with the drug (supersaturated matrix which may contain very tiny crystals); purple spectrum indicating areas with crystalline drug); IR reflectance image (left), optical image (right) and the IR spectrum of the point of interest (bottom) of the surfaces of the buccal patches with (b) $10 \%$, (c) $20 \%$ and (d) $30 \%$ felodipine loading.

6. Figure 4. Micro-CT images of placebo surface image (left) and cross-section (right).

7. Figure 5. Micro-CT images of surface (left) and cross-section (right) buccal patches with $10 \%$ felodipine loading 


\section{Visual appearances of the HME-IM patches}

The physical appearances of the HME extrudates and HME-IM patches are shown in Figure 1. All extrudates and patches are opaque in colour. With increasing the drug loading, the opacity increases. This is an indication of the presence of increased amount of crystalline materials (contributions from both crystalline PEO/PEG and crystalline felodipine).
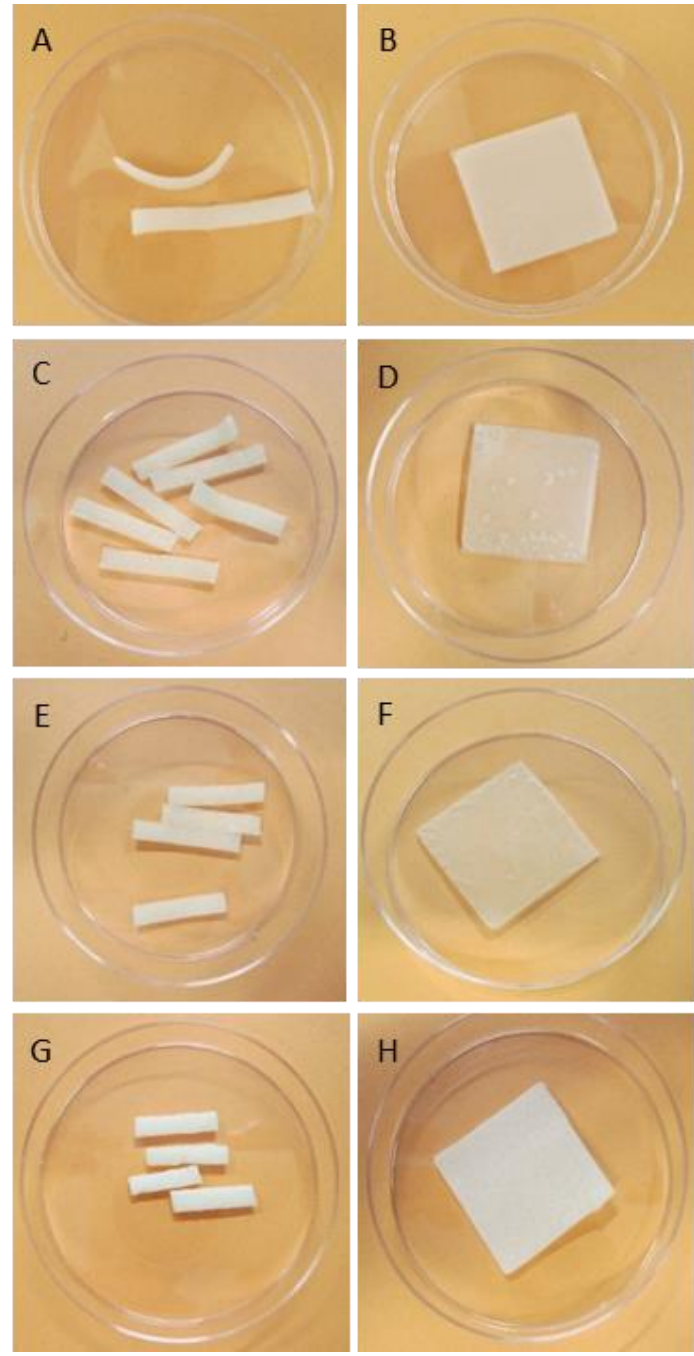

Figure 1. Optical images of the felodipine extrudates and patches: A) Placebo extrudate, B) Placebo buccal patch, C) $10 \% \mathrm{w} / \mathrm{w}$ felodipine extrudate, D) $10 \%$ felodipine buccal patch, E) $20 \% \mathrm{w} / \mathrm{w}$ felodipine extrudate, F) $20 \%$ felodipine buccal patch, G) 30\% w/w felodipine extrudate, H) 30\% felodipine buccal patch. 
Estimation of felodipine-PEG/PEO miscibility via solubility parameter calculated by ground contribution method

Theoretical approach of using group contribution methods was adapted to predict the miscibility of felodipine and PEG/PEO polymeric mixture. Two group contribution methods, Hoftzyer-Van Krevelen and Hoy methods, were used to calculate the Hansen solubility parameter [1-3]. Using Hoftyzer and Van Krevelen method, the solubility parameters of the drug and polymer can be calculated using Eq. 1-4.

$\delta=\sqrt{\delta_{d}^{2}+\delta_{p}^{2}+\delta_{h}^{2}} \ldots \ldots \ldots$ Eq. 1

$\delta_{d}=\frac{\Sigma \mathrm{Fdi}}{\mathrm{V}} \ldots \ldots \ldots . . . . \mathrm{Eq} .2$

$\delta_{p}=\frac{\sqrt{\Sigma \mathrm{F}^{2} \mathrm{pi}}}{\mathrm{V}} \ldots \ldots \ldots$ Eq. 3

$\delta_{\mathrm{h}}=\sqrt{\frac{\sum E \mathrm{Eh}}{\mathrm{V}}} \ldots \ldots \ldots . .$. Eq. 4

Where $\delta$ is solubility parameter $\left(\mathrm{MJ} / \mathrm{m}^{3}\right)^{1 / 2}, \mathrm{~F}_{\mathrm{di}}$ is the dispersion component of the molar attraction constant $\left(\mathrm{MJ} / \mathrm{m}^{3}\right)^{1 / 2} \cdot \mathrm{mol}^{-1}, \mathrm{~F}_{\mathrm{pi}}$ is the polar component of the molar attraction constant $\left(\mathrm{MJ} / \mathrm{m}^{3}\right)$. $\mathrm{mol}^{-1}, \mathrm{E}_{\mathrm{hi}}$ is hydrogen bonding energy component $\mathrm{J}_{\mathrm{mol}} \mathrm{m}^{-1}$ and $\mathrm{V}$ is molar volume $\mathrm{cm}^{3} \cdot \mathrm{mol}^{-1}$.

Using Hoy group contribution method, the solubility parameter of the drug and polymer are calculated separately using Eq. 5 and 6, respectively.

$\delta=\frac{\left(\mathrm{F}_{\mathrm{i}}+\mathrm{B}\right)}{\mathrm{V}} \ldots \ldots \ldots \ldots$..... 5
$\delta=\frac{\left(\mathrm{F}_{\mathrm{i}}+\mathrm{B} / n\right)}{\mathrm{V}} \ldots \ldots \ldots \ldots$ Eq. 6 
Where $\delta_{\mathrm{t}}$ is total Solubility parameter $\left(\mathrm{MJ} / \mathrm{m}^{3}\right)^{1 / 2}, \mathrm{~F}_{\mathrm{t}}$ is molar attraction function $\left(\mathrm{MJ} / \mathrm{m}^{3}\right)^{1 / 2} \cdot \mathrm{mol}^{-1}, \mathrm{~B}$ is base value (which is 277 in this case [3]), $\mathrm{n}$ is the number of repeating units per effective chain segment of the polymer and $\mathrm{V}$ is the molar volume $\mathrm{cm}^{3} \cdot \mathrm{mol}^{-1}$.

Tables 1-4 show the values of the parameters used for calculating the solubility parameters $(\delta)$ of the model drug and PEG/PEO that are determined based on the chemical structure of the model drug and the monomeric unit of PEG/PEO (shown in Figure 1). Because PEG 4000 and PEO WSR 1105 has the same monomeric structure and only differ in molecular weights, the solubility parameter can only be considered the same when group contribution method is applied.

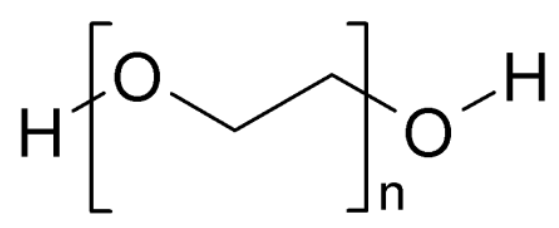<smiles>CCOC(=O)C1=C(C)NC(C)=C(C(=O)OC)C1c1cccc(Cl)c1Cl</smiles>

Figure 2. Chemical structures of PEG 4000 and PEO WSR 1105 (monomer) and felodipine. 
Table 1. Hoftyzer and Van Krevelen group contribution parameters used for PEG/PEO calculations

\begin{tabular}{|l|l|l|l|}
\hline $\begin{array}{l}\text { Structural } \\
\text { Group }\end{array}$ & $\mathbf{F}_{\mathrm{di}}\left(\mathbf{M J} / \mathbf{m}^{3}\right)^{\mathbf{1} / 2} \cdot \mathbf{m o l}^{-1}$ & $\mathbf{F}_{\mathbf{p i}}^{2}\left(\mathbf{M J} / \mathbf{m}^{\mathbf{3}}\right) \cdot \mathbf{m o l}^{-2}$ & $\mathbf{E h}_{\mathbf{i}} \mathbf{J}_{\mathbf{~ m o l}} \mathbf{~}^{-1}$ \\
\hline $2-\mathrm{CH}_{2}$ & $2 \times 270$ & 0 & 0 \\
\hline $1-\mathrm{O}$ & $1 \times 100$ & 160000 & 4000 \\
\hline$\Sigma$ & 640 & 160000 & 4000 \\
\hline
\end{tabular}

e detailed calculation of the solubility parameter of PEG 4000/ PEO WSR 1105 polymers using Hoftyzer and Van Krevelen method is shown below.

$$
\begin{aligned}
& \mathrm{V}=37.55 \mathrm{~cm}^{3} \cdot \mathrm{mol}^{-1} . \\
& \delta d=\frac{\sum \mathrm{Fdi}}{\mathrm{V}}=17.04\left(\mathrm{MJ} / \mathrm{m}^{3}\right)^{1 / 2} \\
& \delta p=\frac{\sqrt{\Sigma \mathrm{F}^{2} \mathrm{pi}}}{\mathrm{V}}=400\left(\mathrm{MJ} / \mathrm{m}^{3}\right)^{1 / 2} \\
& \delta h=\sqrt{\frac{\sum E h i}{V}}=106.52\left(\mathrm{MJ} / \mathrm{m}^{3}\right)^{1 / 2} \\
& \delta=\sqrt{\delta_{d}^{2}+\delta_{p}^{2}+\delta_{h}^{2}}=22.59\left(\mathrm{MJ} / \mathrm{m}^{3}\right)^{1 / 2}
\end{aligned}
$$

Table 2. Hoy group contribution parameters used for PEG/PEO calculations

\begin{tabular}{|l|l|l|l|}
\hline Structural Group & $\mathbf{F}_{\mathbf{t}}\left(\mathbf{M J} / \mathbf{m}^{\mathbf{3}}\right)^{\mathbf{1} / 2} \cdot \mathbf{m o l}^{-1}$ & $\Delta \mathbf{T}$ & $\mathbf{V} \mathbf{c m}^{\mathbf{3}} \cdot \mathbf{m o l}$ \\
\hline $2-\mathrm{CH}_{2}$ & $2 \times 269$ & 0.02 & 15.55 \\
\hline $1-\mathrm{O}$ & $1 \times 235$ & 0.018 & 6.45 \\
\hline$\Sigma$ & 773 & 0.058 & 37.55 \\
\hline
\end{tabular}


The detailed calculation of the solubility parameter of PEG 4000/ PEO WSR 1105 polymers using Hoy method is shown below.

$\mathrm{V}=37.55 \mathrm{~cm}^{3} \cdot \mathrm{mol}^{-1}$

$\mathrm{n}=0.5 / \Delta \mathrm{T}=8.62$

$\delta t=\frac{\left(\mathrm{F}_{\mathrm{i}}+\mathrm{B} / n\right)}{\mathrm{V}}=21.44\left(\mathrm{MJ} / \mathrm{m}^{3}\right)^{1 / 2}$

Table 3. Hoftyzer and Van Krevelen group contribution parameters used for felodipine calculations

\begin{tabular}{|c|c|c|c|c|}
\hline Structural Group & $\begin{array}{l}\text { No. of } \\
\text { groups }\end{array}$ & $F_{d i}\left(M J / m^{3}\right)^{1 / 2} \cdot m^{-1}$ & $\underset{\mathrm{mol}^{-2}}{\mathrm{~F}_{\mathrm{in}}^{2}}\left(\mathrm{MJ} / \mathrm{m}^{3}\right)$ & $\mathrm{Eh}_{\mathrm{i}} \mathrm{J} \cdot \mathrm{mol}^{-1}$ \\
\hline $\mathrm{CH}_{3}$ & 4 & $4 * 420$ & 0 & 0 \\
\hline $\mathrm{CH}_{2}$ & 1 & 270 & 0 & 0 \\
\hline $\mathrm{COO}$ & 2 & $2 * 390$ & $(490)^{2}$ & 7000 \\
\hline $\begin{array}{l}\text { tri-substituted } \\
\text { benzene ring }\end{array}$ & 1 & 1270 & $(110)^{2}$ & 0 \\
\hline$=\mathrm{C}<$ & 4 & $4 * 70$ & 0 & 0 \\
\hline $\mathrm{CH}$ & 1 & 200 & 0 & 0 \\
\hline $\mathrm{NH}$ & 1 & 160 & $(210)^{2}$ & 3100 \\
\hline $\mathrm{Cl}$ & 2 & $2 * 450$ & $(550)^{2}$ & 400 \\
\hline Ring & 1 & 190 & 0 & 0 \\
\hline$\Sigma$ & & 5730 & 1141400 & 17900 \\
\hline
\end{tabular}

The detailed calculation of the solubility parameter of felodipine using Hoftyzer and Van Krevelen method is shown as below.

$$
\begin{aligned}
& \mathrm{V}=304.77 \mathrm{~cm}^{3} \cdot \mathrm{mol}^{-1} \\
& \delta_{d}=\frac{\Sigma \mathrm{F}_{\mathrm{di}}}{\mathrm{V}}=18.80\left(\mathrm{MJ} / \mathrm{m}^{3}\right)^{1 / 2} \\
& \delta_{p}=\frac{{\sqrt{\Sigma \mathrm{F}_{\mathrm{pi}}^{2}}}_{\mathrm{V}}^{2}}{{ }^{2}}=3.51\left(\mathrm{MJ} / \mathrm{m}^{3}\right)^{1 / 2}
\end{aligned}
$$




$$
\begin{aligned}
& \delta_{h}=\sqrt{\frac{\Sigma \mathrm{E}_{\mathrm{hi}}}{\mathrm{V}}}=7.66\left(\mathrm{MJ} / \mathrm{m}^{3}\right)^{1 / 2} \\
& \delta=\sqrt{\delta_{d}^{2}+\delta_{p}^{2}+\delta_{h}^{2}}=20.60\left(\mathrm{MJ} / \mathrm{m}^{3}\right)^{1 / 2}
\end{aligned}
$$

Table 4. Hoy group contribution parameters used for felodipine calculations

\begin{tabular}{|l|l|l|l|}
\hline Structural Group & No. of groups & $\mathbf{F}_{\mathbf{t}}\left(\mathbf{M J} / \mathbf{m}^{\mathbf{3}}\right)^{\mathbf{1} / \mathbf{2}} \cdot \mathbf{m o l}^{-1}$ & $\mathbf{V ~ c m ~}^{\mathbf{3}} \cdot \mathbf{m o l}$ \\
\hline $\mathrm{CH} 3$ & 4 & $4 * 303.5$ & 86.2 \\
\hline $\mathrm{CH} 2$ & 1 & 269 & 15.55 \\
\hline $\mathrm{COO}$ & 2 & $2 * 640$ & 47.4 \\
\hline $\mathrm{C}$ ar & 1 & 201 & 51.94 \\
\hline $\mathrm{CH}$ ar & 4 & $4 * 241$ & 53.68 \\
\hline $\mathrm{NH}$ & 1 & 368 & 11 \\
\hline $\mathrm{Cl}$ & 1 & 330 & 39 \\
\hline 6 ring & 2 & $2 *-48$ & 0 \\
\hline Ortho & 1 & 20.2 & 0 \\
\hline Meta & 1 & 13.5 & 0 \\
\hline$\Sigma$ & & 6147.7 & 304.77 \\
\hline
\end{tabular}

The detailed calculation of the solubility parameter of felodipine using Hoftyzer and Van Krevelen method is shown as below.

$$
\begin{aligned}
& \mathrm{V}=304.77 \mathrm{~cm}^{3} \cdot \mathrm{mol}^{-1} \\
& \delta_{t}=\frac{(\mathrm{F}+\mathrm{B})}{\mathrm{V}}=21.08\left(\mathrm{MJ} / \mathrm{m}^{3}\right)^{1 / 2}
\end{aligned}
$$

It can be seen that the difference between the solubility parameters of the drug and the amorphous fraction of the polymeric blend is less than 2 in case of Hoftyzer and Van Krevelen method and less than 0.5 according to Hoy method. This indicates that both methods agree the high degree of miscibility between the drug and PEG/PEO [4]. 


\section{Melting point depression of drug-polymer blends}

Table 5 summarizes the depression of the melting transition of PEG and PEO in the drug loaded patches. The data is obtained from Figure 1c in the main manuscript. It can be seen that with increasing the drug load from $10 \%$ to $20 \%$, the melting onset and peak temperatures both depressed 3.9 and $5^{\circ} \mathrm{C}$, respectively. This depression is likely caused by the dissolution (by melting) of felodipine in the PEG/PEO. However, the patches with $30 \%$ drug loading, no further depression of the melting of PEG/PEO is observed. This may be partially attributed to the supersaturation of felodipine in the PEG/PEO phase (as evidenced by the presence of crystalline drug in these patches), thus no additional drug is dissolved in PEG/PEO phase to cause further melting depression. The melting enthalpy value can be used as a rough measure of the crystallinity level of the polymers. There is no significant change in the crystallinity of the polymers are observed after drug incorporation.

Table 5. Melting point $\left(\mathrm{T}_{\mathrm{m}}\right)$ depression of PEG/PEO blend caused by drug loading in different patches (3 replicates for each sample) DSC $10^{\circ} \mathrm{C} / \mathrm{min}$.

\begin{tabular}{|l|l|l|l|}
\hline Loading (w/w \%) & $\Delta \mathbf{H}_{\mathbf{f}}(\mathbf{J} / \mathbf{g})$ & $\mathbf{T}_{\mathbf{m}}$ Onset $\left({ }^{\circ} \mathbf{C}\right)$ & $\mathbf{T}_{\mathbf{m}}$ Peak $\left({ }^{\circ} \mathbf{C}\right)$ \\
\hline Placebo 0 & $126.8 \pm 1.0$ & $59.0 \pm 0.1$ & $64.4 \pm 0.2$ \\
\hline $\mathbf{1 0}$ & $115.2 \pm 2.0$ & $55.7 \pm 0.3$ & $62.5 \pm 0.1$ \\
\hline $\mathbf{2 0}$ & $94.6 \pm 1.0$ & $54.0 \pm 0.5$ & $60.5 \pm 0.1$ \\
\hline $\mathbf{3 0}$ & $87.0 \pm 3.2$ & $55.4 \pm 0.1$ & $60.1 \pm 0.0$ \\
\hline
\end{tabular}

\section{Analysis of the $T_{g}$ regions of the patches}

Table 6 shows the detailed measurements of the values of $\Delta C_{P}$ and $T_{g}$ of the glass transition regions of all physical mixtures and patches. It can be clearly seen that placebo mixtures and patches have the lowest $T_{g}$ and the incorporation of felodipine 
increases the $T_{g}$ of the mixtures and patches. With increasing the drug loading from 0 $20 \%$, the $T_{g}$ and $\Delta C_{P}$ values increase indicating the increased amount of amorphous material in the patches. However, further increasing the drug loading to $30 \%$ led to the presence of crystalline drug in the formulation and this is also reflected by the reduced $T_{g}$ and $\Delta C_{P}$ values in comparison to the values of the samples with $20 \%$ drug loading.

Table 6. Detailed $\mathrm{T}_{\mathrm{g}}$ and $\Delta \mathrm{C}_{\mathrm{P}}$ values of the glass transition of physical mixtures and HME-IM patches with different drug loading.

\begin{tabular}{|c|c|c|c|c|c|c|c|c|}
\hline Drug loading & \multicolumn{2}{|c|}{ Placebo } & \multicolumn{2}{c|}{$10 \%$ w/w loading } & \multicolumn{2}{c|}{ 20\% w/w loading } & 30\% w/w loading \\
\hline Form & PM & Patch & PM & Patch & PM & Patch & PM \\
\hline$\Delta \mathrm{C}_{\mathrm{P}}(\mathrm{J} / \mathrm{g})$ & $0.18 \pm 0.03$ & $0.13 \pm 0.01$ & $0.25 \pm 0.03$ & $0.30 \pm 0.02$ & $0.23 \pm 0.01$ & $0.35 \pm 0.03$ & $0.25 \pm 0.00$ & $0.24 \pm 0.02$ \\
\hline $\mathrm{T}_{\mathrm{g}}\left({ }^{\circ} \mathrm{C}\right)$ mid point & $-62.1 \pm 0.5$ & $-60.8 \pm 0.6$ & $-56.4 \pm 0.1$ & $-51.0 \pm 0.2$ & $-55.4 \pm 0.3$ & $-38.7 \pm 0.2$ & $-55.9 \pm 0.0$ & $-51.3 \pm 0.5$ \\
\hline
\end{tabular}

*PM stands for physical mixtures

\section{IR imaging of the patches}

The IR reflectance images of the surfaces of the patches are shown in Figure 3. The difference colour regions represent areas with different IR sepctra (Figure 3a). Although the IR images were constructed using reflectance information of the sample surfaces, it can be seen that the IR spectra of the areas with red, green and blue are distictively different, indicating areas with different colour are also with different chemical composition (Figure 3a). It can be seen that the IR images of the surfaces of the placebo and $10 \%$ loaded patches are dominated by red colour with a spectrum containing little contribution of drug spectrum (Figure $3 b$ and c). Increased hetergeniety of the colour differences are observed in the patches with higher drug loadings. As seen in Figure $3 \mathrm{~d}$ and e, multicolor domains can be clearly observed at 
the surfaces of the $20 \%$ and $30 \%$ loaded patches. The sizes of the domains are larger for $20 \%$ than for $30 \%$ patches. The results are good indications of the presence of phase separation in the patches with high drug loading.
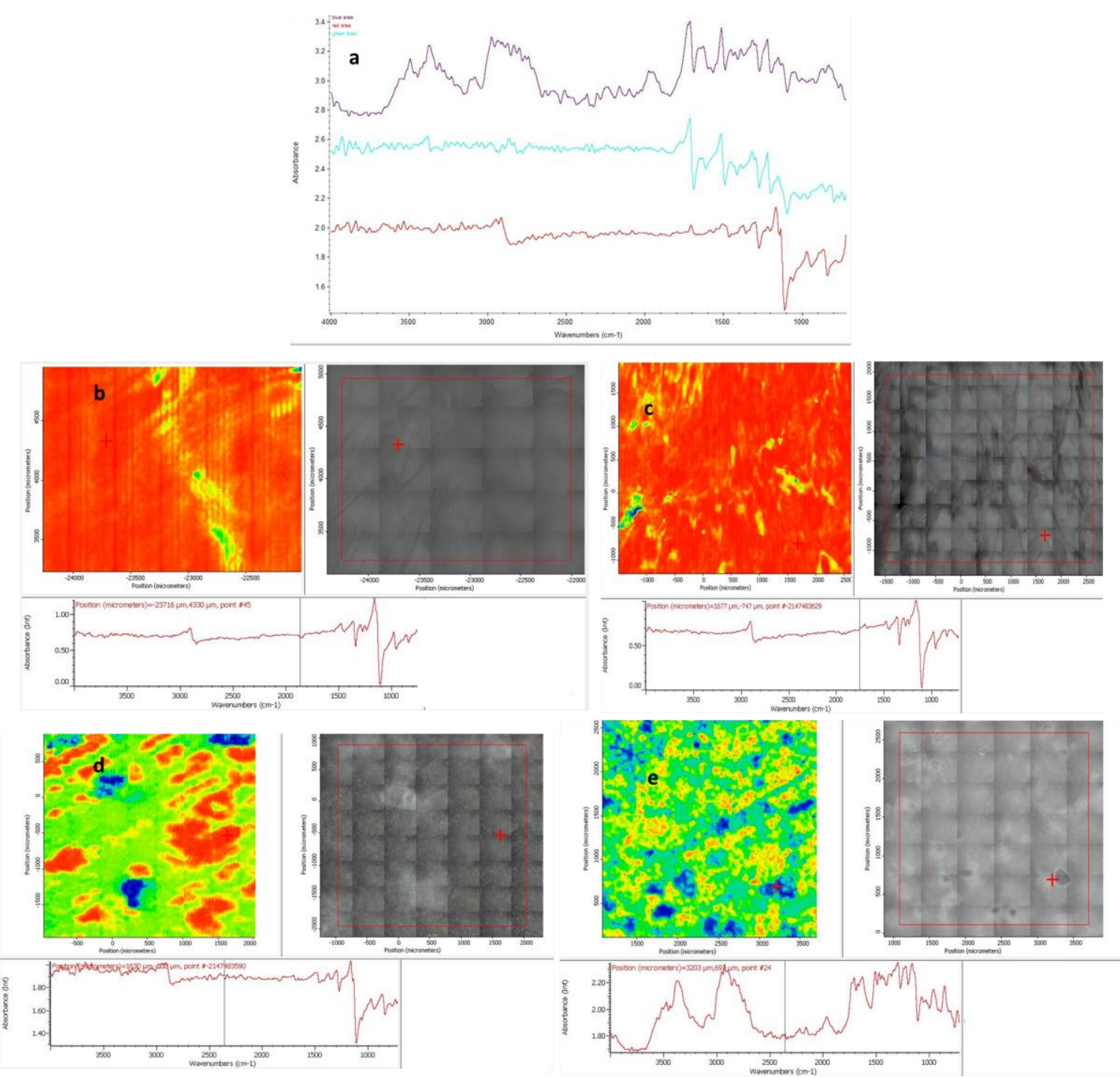

Figure 3. (a) IR reflectance spectra coding for the composition of different colors in the IR images. Red spectrum indicates areas containing drug as molecularly dispersed or amorphous form; green spectrum indicating areas indicating areas rich with the drug (supersaturated matrix which may contain very tiny crystals); purple spectrum indicating areas with crystalline drug); IR reflectance image (left), optical image 
(right) and the IR spectrum of the point of interest (bottom) of the surfaces of the buccal patches with (b) placebo, (c) 10\%, (d) $20 \%$ and (e) $30 \%$ feloidpine loading.

\section{X-ray Micro-CT imaging of placebo and $10 \%$ drug loaded patches}

Figures 4 and 5 show the micro-CT images of the placebo and patches with $10 \%$ drug loading. It can be seen that there are dark and light blue color present in the 3D images of the patches. This effect is within the noise level of the measurement thus not a true feature of the samples. Therefore no phase separation is detected using micro-CT under the limit of detection of micro-CT.

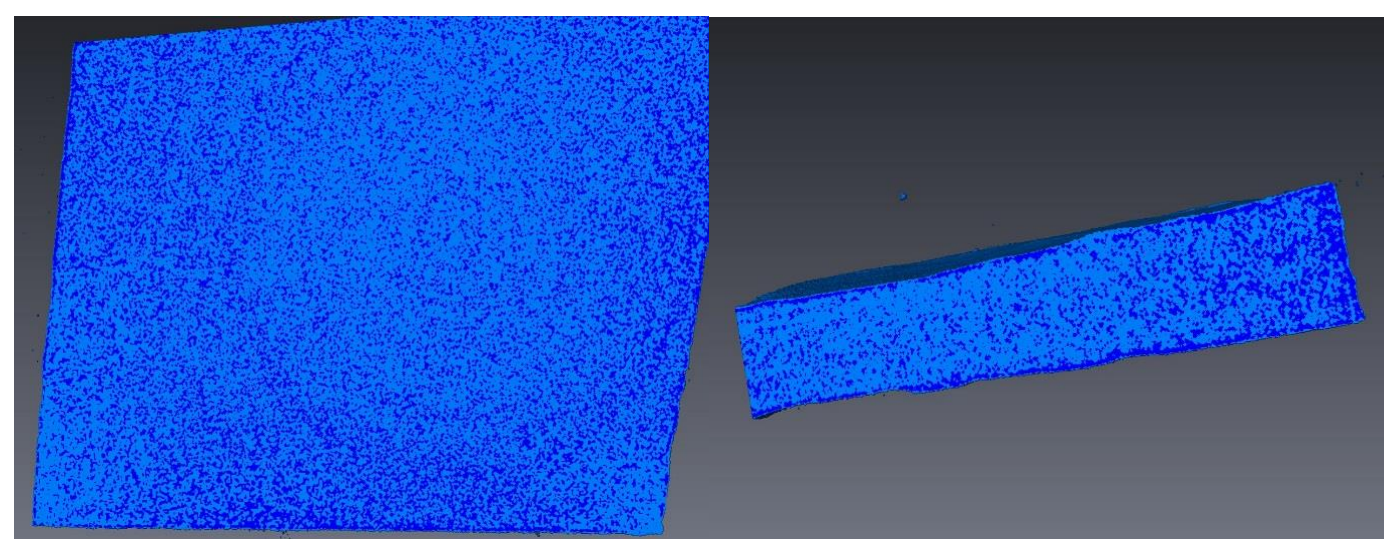

Figure 4. Micro-CT images of placebo surface image (left) and cross-section (right).

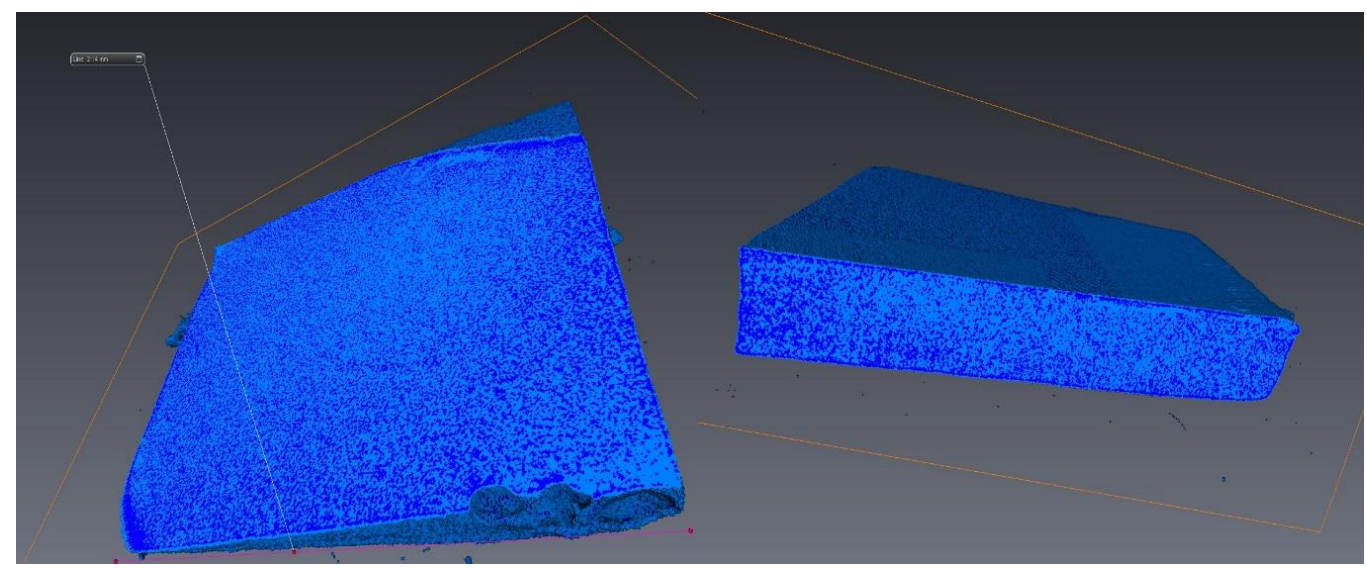

Figure 5. Micro-CT images of surface (left) and cross-section (right) buccal patches with $10 \%$ felodipine loading

\section{Reference:}


(1) Van Krevelen, D. W.; Hoftyzer, P. J. Practical evaluation of the $[\eta]-\mathrm{M}$ relationship. III. Estimation of the exponent a. Journal of Applied Polymer Science 1967, $11,(11), 2189-2200$.

(2) Hoy, K. L. New values of the solubility parameters from vapor pressure data. Journal of paint technology 1970, 42, (541), 76-118.

(3) Van Krevelen, D. W.; Te Nijenhuis, K., Chapter 7 - Cohesive Properties and Solubility. In Properties of Polymers (Fourth Edition), by, D. W. V. K.; Nijenhuis, K. T., Eds. Elsevier: Amsterdam, 2009; pp 189-227.

(4) Forster, A.; Hempenstall, J.; Tucker, I.; Rades, T. Selection of excipients for melt extrusion with two poorly water-soluble drugs by solubility parameter calculation and thermal analysis. International Journal of Pharmaceutics 2001, 226, (1-2), 147-161. 